\title{
Lima en la década de 1870 , una ciudad para el cincuentenario de la Independencia
}

\author{
Lima in the 1870s: a city for the fiftieth anniversary \\ of independence of Peru
}

Juan Luis Orrego Penagos

Universidad de Lima

\section{RESUMEN}

El primer gran intento de transformación urbana de Lima en su historia republicana se realizó en la década de 1870, coyuntura que coincidió con la conmemoración del cincuentenario de la Independencia. El presente ensayo, testimonia dichos cambios, como la destrucción de la muralla virreinal y la habilitación de terrenos para avenidas anchas, plazas, nuevos barrios residenciales y modernos espacios públicos, como el Parque y el Palacio de la Exposición. Se analiza, además, la principal actividad celebratoria de la simbólica efeméride, como lo fue la Gran Exposición de 1872. El estudio finaliza con la conversión del Palacio de la Exposición como nueva sede del Museo Nacional, cuya colección debía servir como vehículo a la construcción de una identidad nacional.

Palabras clave:

historia de Lima, memoria histórica, bicentenario, identidad nacional

\section{ABSTRACT}

The first great attempt of urban transformation of Lima in its republican history was performed in the 1870s, a situation that coincided with the commemoration of the fiftieth anniversary of the independence of Peru. This essay testifies to these changes, such as the destruction of the viceroyalty wall and the provision of lands for wide avenues, squares, new residential neighborhoods and modern public spaces, including the Parque de la Exposición and the Palacio de la Exposición. It also analyzes the main celebratory activity of the symbolic event, as was the Great Exhibition of 1872. The study ends with the conversion of the Palacio de la Exposición into the new headquarters of the National Museum, the collection of which was to serve as a vehicle for the construction of a national identity.

Keywords:

history of Lima, historical memory, bicentennial, national identity 
E la década de 1870 debían llevarse a cabo las actividades conmemorativas del cincuentenario de la Independencia, pues se cumplía medio siglo del arribo de las tropas de San Martín a la bahía de Paracas (1820), de la proclamación de la Independencia en la Plaza de Armas de Lima (1821) y de la batalla de Ayacucho (1824), proceso que puso fin al poder borbónico en la América andina. Lima, la antigua capital del Virreinato, y ahora también epicentro de la joven República, debía aprovechar esta efeméride para implementar un ambicioso programa de reformas, especialmente en su proyección urbanística. Así, al menos, lo entendieron sus autoridades.

A nuestro criterio, hasta esta conmemoración patriótica, Lima había atravesado por tres grandes etapas históricas. La primera es su legado prehispánico, cuando sus antiguos habitantes, desde el Intermedio Temprano (100 d. C., aproximadamente), fueron aprovechando las aguas del Chillón, Rímac y Lurín, e implementaron un complejo sistema de canales de regadío dándole vida a esta parte de la costa central, además de construir una red de oráculos o centros ceremoniales. La segunda se inició con la fundación de la Ciudad de los Reyes (1535), emprendida por Francisco Pizarro y su hueste, que tuvo que adaptar el damero (de influencia romana) al entramado ya existente y levantar la ciudad bajo los criterios del siglo xvi, morisco y renacentista. Con el advenimiento del Barroco, entre los siglos XVII y xVIII, llegó el apogeo de la capital del Virreinato, con sus templos, palacios y monasterios. Todo aquel esplendor, literalmente, se vino abajo con el cataclismo de 1746, que casi no dejó nada en pie. A partir de entonces, se inició la tercera etapa, que supondría la reconstrucción de la ciudad, bajo la dirección de los virreyes borbónicos, utilizando cánones afrancesados y neoclásicos.

Asumimos que de 1746 a 1870 hubo una continuidad, pues la Independencia no supuso ningún cambio significativo en la fisonomía de Lima. Las obras que emprendieron virreyes como el conde de Superunda, Manuel de Amat o Fernando de Abascal tuvieron vigencia hasta pasado el ecuador del siglo xIx. Para empezar, los veinte años que siguieron a la Independencia fueron tan inestables que no hubo tiempo ni dinero para invertirlo en la ciudad. Con la llegada del auge guanero, durante los gobiernos de Ramón Castilla y José Rufino Echenique, contra lo que podríamos suponer, lo que se introdujo no varió notablemente el matriz de la herencia virreinal.

¿Cuáles fueron las principales obras de esta época de bonanza? Quizá las más emblemáticas fueron la construcción del ferrocarril al Callao (1851); el estreno del alumbrado a gas (1855); la remodelación de la Alameda de los Descalzos con esculturas italianas de mármol y una reja de fierro (1856); la inauguración del ferrocarril a Chorrillos (1858); la instalación del monumento a Simón Bolívar en la antigua Plaza de la Inquisición (1859); la colocación de un monumento a Cristóbal Colón en la desaparecida Alameda de Acho (1860); la trasformación de la antigua Plaza de Armas, retirando el mercado, para darle un aspecto más ordenado, quizá más "cívico", con piso empedrado, bancas y esculturas de mármol (1860); y la moderna penitenciaría, en los extramuros de la ciudad (1862). Pero no eran cambios estructurales, pues Lima seguía atrapada en su antigua muralla, con los problemas y limitaciones que esta generaba. Por ello, la decisión de demoler aquel cinturón de piedra y adobe, construido por el virrey Palata hacia 1680, sí marcó un antes y un después en el desarrollo urbano de nuestra capital.

\section{Obras públicas y contexto político}

Desde 1868, gobernaba el país el coronel José Balta. Su régimen, que culminó dramáticamente en 1872 , cuando fue asesinado por los hermanos Gutiérrez, se propuso revertir el errático uso que hasta entonces el país le había dado a las ganancias obtenidas por la venta del guano en un vasto plan de obras de infraestructura, cuyo nivel más alto fueron los ferrocarriles, muchos de estos construidos por el empresario norteamericano Henry Meiggs'. Su gobierno, además, debía organizar los fastos por los cincuenta años de trayectoria republicana.

El cincuentenario, entonces, era el marco adecuado para modernizar Lima y liberarla de sus rezagos virreinales, y el punto de mira era la muralla. El objetivo no solo era permitir la expansión urbana de la capital, sino también mejorar la higiene pública, otro signo de la modernidad. Los limeños acumulaban basura al pie de la vieja muralla que, además, impedía la limpieza del aire, con el

1 Las obras de infraestructura también se realizaron en el Callao y otros puertos del litoral, como lquique, Mollendo, Pisco, Eten, Salaverry y Pacasmayo; varios proyectos de irrigación en la costa acompañaron esta fiebre constructora. 
riesgo de propagación de enfermedades y epidemias. En este sentido, la fiebre amarilla que se desató en 1868 firmó su sentencia de muerte ${ }^{2}$. En síntesis, hacia 1870, cuando los limeños ya bordeaban los cien mil, la obra de Palata ya no podía contener la ciudad y, de hecho, se había convertido en un freno para su desarrollo.

El plan modernizador de los asesores de Balta incluía el ensanche de la Lima histórica. La liberación de las zonas ocupadas por la muralla daría paso a nuevas avenidas y calles, alrededor de las cuales se venderían terrenos desocupados, por lotes. Con esto, además, se produciría la baja de los arrendamientos y se corregiría el hacinamiento de los limeños en el centro de la ciudad. Así, el 1 de diciembre se nombra una comisión para elaborar los planos de los terrenos que quedarían libres luego de la demolición.

Fue también Henry Meiggs quien obtuvo la licitación para la demolición. Por su lado, el ingeniero agrónomo Luis Sada di Carlo, de origen italiano, tuvo a su cargo el levantamiento del nuevo plano de Lima y el estudio de un programa de regulación y ornato público integral. Según el contrato de demolición, Meiggs compraría luego el área despejada³. Se empezaría entonces a medir y tasar toda el área implicada para que el trazo de Sada fuera el Primer Plan Regulador de la Ciudad. La idea de una ciudad sin límites debía contar con un tejido de grandes avenidas, tipo boulevards, y llegar a tener una gran alameda a lo largo de las riberas del Rímac.

Si bien el nuevo plan urbanístico estaba inspirado en las ciudades europeas, especialmente París, a diferencia de los que hizo el barón de Hausmann en la capital francesa, no se quiso intervenir el centro histórico, sino crear una segunda Lima alrededor de la histórica y que avanzara en distintas direcciones. Este tipo de ensanche más recordaría a lo realizado en muchas ciudades españolas que tendían a respetar el antiguo núcleo urbano 4 . Cabe destacar que el plan diseñado por Luis Sada tuvo el consenso de los otros grupos políticos de la época, como el Partido Civil, que venció en las elecciones de 1871 e inició sus funciones de gobierno al año siguiente.

Al sur de la nueva zona, se construiría el Palacio de la Exposición, rodeado de una extensa zona de hermosos jardines y glorietas, que sirvió de escenario para la realización de la gran Exposición Nacional de 1872 con motivo del Cincuentenario de la Independencia. Asimismo, otras obras en concordancia con este espíritu modernizador fueron la apertura de una carretera de Lima al Callao, la ampliación de la línea telegráfica a las provincias, el Jardín Botánico, la estación de Monserrat para el Ferrocarril Central, la construcción de un puente de fierro sobre el río Rímac (más tarde llamado puente Balta) ${ }^{5}$, la inauguración del moderno

2 Varios historiadores han subrayado lo inútil que resultó la muralla en caso de defensa. Además, durante el Virreinato, los limeños siempre tuvieron la idea de que los asuntos que preocupaban a España, como la guerra y los piratas, estaban muy lejos de su ciudad como para alertarse. Pensaban que cualquiera que quisiera atacar Lima debía cruzar el Atlántico, sortear el peligroso Cabo de Hornos y doblar al Pacífico; luego, encontrar un lugar adecuado donde dejar el barco (o los barcos) y, finalmente, tratar de cruzar un largo desierto sin caballos. El riesgo al fracaso era muy alto; por ello, la naturaleza era la que permitía disfrutar de una relativa paz en la ciudad. En último caso, solo con fortificar el Callao bastaba. Lima no era un lugar tan expuesto como La Habana, San Juan de Puerto Rico o Cartagena de Indias. Al final, respecto a su uso o función, sembró una división en dos espacios: lo intramuros, es decir, lo que estaba dentro de los muros de la ciudad, y lo extramuros, lo que ocurría fuera de los muros o fuera de la ciudad. En otras palabras, a través de estos espacios se intentó controlar la vida económica y social de la capital del Virreinato. Sus diez puertas eran las que permitían el control social, o al menos esa era la intención, ya que cualquier persona, por ejemplo, no podía entrar a la Plaza de Armas. Las puertas de la ciudad estaban vigiladas, sobre todo, de noche. El acceso y la salida estaban restringidos por las noches, cuando las puertas se cerraban con la puesta de sol y se abrían al alba del día siguiente. Con el tiempo, debido al crecimiento de la población, la muralla marcó otra diferencia peligrosa. La gente que vivía en los extramuros se fue tugurizando y devino en un sector social lumpen. Cabe destacar que hubo una demolición parcial de la muralla en 1808, cuando se construyó el Cementerio General y se necesitó un acceso amplio al nuevo camposanto que inauguró el virrey Abascal.

3 Meiggs cobró 211000 soles por derribar la construcción colonial. Pero, como el espacio que ocupaba la Muralla no era suficiente para construir avenidas de cincuenta metros de ancho (las de circunvalación), el empresario fue autorizado por el Gobierno para adquirir por expropiación forzosa los terrenos complementarios. Como anota Guillermo Lohmann, Meiggs, "arriscado aventurero decidido a explotar una modalidad de lucro con la propiedad inmueble desconocida en el país: comprar a precios bajos para vender a uno superior beneficiándose directamente de alguna mejora ambiental. En el lapso de dos años, tras ofrecerse como único postor, derruyó la cerca por un costo reducido, eso sí a cambio de la concesión de fajas del terreno adyacentes a ella, y que especulativamente habían granjeado una considerable plusvalía al tener ahora por frente la gran alameda de circunvalación, de 50 metros de ancho, al estilo de los bulevares parisienses" (Günther y Lohmann 1992, p. 209).

4 El caso de Lima recuerda a lo que ocurrió cuando se derribaron las murallas de Barcelona (1854), Sevilla (1863) y Valencia (1865) o La Habana (1863).

5 El puente Balta, sobre el río Rímac, se construyó en la segunda mitad del siglo xix. Se trató del primer puente de fierro levantado en Lima, y llevó para siempre el nombre del mandatario que contrató la obra. Antes, había allí un puente primitivo de madera, pero la administración de Balta dispuso la construcción de uno de fierro fundido en Francia por la fábrica Boigues Rambourgs Co, a un costo de trescientos mil soles. Los primeros trabajos se iniciaron el 19 de marzo de 1869, siendo el empresario de la obra Enrique Armero y el ingeniero Felipe Arancibia. Las obras recién fueron concluidas entre 1918 y 1919. Por ello, la inauguración final la hizo el presidente Augusto B. Leguía. 
Hospital Dos de Mayo y la conversión del viejo puerto de Ancón en un balneario al estilo europeo, unido a Lima por un ferrocarril. Lima también debía estar abierta a la modernización educativa, con la reorganización de la antigua Universidad de San Marcos, la construcción de un edificio para la Escuela de Artes y Oficios y la fundación de la Escuela de Agricultura, la Escuela de Ingenieros y la Escuela Naval.

\section{El Palacio y los jardines de la Exposición}

Se pensó que al sur de la Lima de entonces se debía dar a la ciudad un gran parque público, que albergara, entre otras atracciones, un edificio para realizar exposiciones de todo género. De esta manera, Lima podía montar el gran evento programado para el cincuentenario: una exposición nacional, para demostrar el grado de adelanto material e industrial que había alcanzado el país en plena eclosión del positivismo.

Por decreto del 2 de agosto de 1869, el presidente Balta ordenó la construcción del Palacio de la Exposición, que debía de estar rodeado de una zona con varios jardines para recreo y espectáculos. Se trataba, en realidad, de un amplio proyecto que serviría "de museo nacional, de jardín zoológico, de taller de ornamentación y escultura, de exposición permanente de todo producto nuevo o desconocido, nacional o extranjero" (Fuentes, 1872, p. 68). La tarea ahora era conseguir el terreno y encargar el diseño de los planos.

El lugar que se eligió para el emplazamiento del nuevo complejo fue a la altura del ingreso sur de la muralla, fuera de las antiguas puertas de Guadalupe y Juan Simón. Por resolución suprema, se adquirieron casi sesenta mil metros cuadrados del fundo San Martín y dos y media fanegadas con dos almudes de la huerta Matamandinga. A este terreno, fue agregada una parcela tomada del fundo Santa Beatriz, adquirida también por el Estado por escritura del 26 de abril de 1870 (Bromley y Barbagelata, 1945) ${ }^{6}$. En total, el Estado habilitó un terreno de 192000 metros cuadrados, colindante con la Penitenciaría de Lima.

El enorme espacio se explicaba, como se señaló, porque el proyecto comprendía la edificación del Palacio de la Exposición, con sus dependencias auxiliares, y la creación de un gran parque para la ciudad, con jardines y arboledas. El polígrafo limeño Manuel Atanasio Fuentes debía supervisar las obras. El diseño del nuevo Palacio, de estilo renacentista, con dos pisos y un patio central, fue obra del pintor y arquitecto genovés Antonio Leonardi. Las columnas estructurales de fierro, mármoles, muebles y objetos de arte fueron traídos de Europa. El hermoso edificio, levantado sobre un rectángulo de ochenta metros de largo por cincuenta y cuatro de ancho, quedó terminado en $1871^{7}$.

La idea del nuevo parque, con sus jardines, arboledas y glorietas, respondía al modelo de urbanización vigente en la mayor parte de las ciudades de Europa y de América del Norte, en el que se insistía en el componente natural como una de las soluciones para mejorar la urbe frente al proceso de industrialización, a la necesidad de que los nuevos espacios públicos debían contar con un entorno natural ${ }^{8}$. En consecuencia, también Lima debía desarrollar un proyecto público en el que la naturaleza urbana apareciera como parte integrante del nuevo espacio citadino y envuelto en un discurso que insistía en el prestigio de la naturaleza, a la que se le atribuían valores pedagógicos, terapéuticos y estéticos.

Para Manuel Atanasio Fuentes y su equipo, Lima, con la destrucción de su muralla, estaba superando sus límites físicos heredados del Virreinato, y el nuevo Parque de la Exposición debía ser concebido en estilo naturalista, como lo venían haciendo los jardineros ingleses desde finales del siglo xvilI. Además, entendía que todo proyecto de este tipo estaba consagrado a la higiene pública y a la difusión de la cultura positiva. Por lo tanto, el nuevo parque debía proporcionar un ocio moralmente aceptable que impulsara la higiene física y moral del ciudadano; era una de las soluciones para

6 Una documentada historia de la venta de estos fundos puede consultarse en Flores-Zúñiga (2008).

7 Años más tarde, por resolución suprema del 27 de agosto de 1889, el Estado entregó el dominio de los parques y sus edificaciones al Concejo Provincial de Lima (Bromley y Barbagelata, 1945).

8 Sabemos que las primeras corrientes higienistas datan de la época de la llustración. Por ello, en Lima ya encontramos "paseos arbolados" desde el siglo xvIII, como la Alameda de Acho, en el barrio de San Lázaro, que servía de acceso a la plaza de toros. En cambio, el Jardín Botánico, implementado por Hipólito Unanue a inicios del siglo xIX, obedecía a fines científicos, no servía como espacio público. 
erradicar problemas sociales como la delincuencia, el alcoholismo, el déficit de vivienda y la insalubridad del entorno urbano.

Era una nueva forma de vivir la ciudad. El Parque de la Exposición debía reemplazar a la vieja Plaza de Armas como punto de encuentro social, en el que los ciudadanos van a observar, a hablar, a encontrarse 9 . Al decir de Jorge Basadre, cumplió su cometido, pues "la Exposición se convirtió en el lugar preferido para los paseos fuera de la capital y llegó a ser el escenario de conciertos y otras actividades culturales y sociales" (Basadre, 2005, vol. 6, p. 53).

A nivel estilístico, el diseño del Parque fue de corte europeo neorrenacentista y contempló la construcción de varios pabellones, incluyendo un zoológico y otras construcciones menores. La nueva gran área verde, en su conjunto, se inspiró en los jardines palaciegos o cortesanos del siglo xVIII, con pequeñas lagunas, fuentes de agua, rincones pintorescos y pequeños edificios alusivos a la antigüedad clásica, el Oriente y la vida pastoril. Asimismo, una elaborada jardinería; una laguna con su isla, a la que se llegaba por un puente de estilo japonés; pabellones venecianos, bizantinos o moriscos; y arcos de triunfo romanos (García Bryce, 1980). Tres puertas monumentales se levantaron a la entrada del Parque, la principal frente a la pared de la Penitenciaría y las otras dos cerca de la línea del ferrocarril a Chorrillos, llamadas Santa María y Vivanco. A la derecha de la entrada principal, había un teatro y a la izquierda, una tienda de refrescos. Dentro, estaba el conservatorio de plantas de tierra cálida, con la glorieta turca. También podía encontrarse una fuente rodeada por largas piedras que formaban un montículo en cuya cima se levantaba una figura colosal que evocaba a Hércules y la hidra. Unos 135 metros había que avanzar desde la entrada hasta el vestíbulo del Palacio.

\section{La Exposición Nacional}

Sin duda, una de las máximas conquistas del genio humano en el siglo xIx fue la Revolución Industrial. Para los más optimistas científicos occidentales, la ciencia era el camino seguro al progreso social y material. Y este casi dogma de fe había que testimoniarlo y, de ser posible, cada año. Fue así que surgió en Europa la idea de organizar exposiciones universales.

Desde la primera que se desarrolló en Londres (1851), sabemos que estas exhibiciones fueron espacios en los que se apreciaba lo que el hombre concebía como progreso en todas las actividades y áreas que comprendía su vida. Eran el estímulo de lo que la inteligencia y actividad humanas podían transformar de la naturaleza, además de incitar, mediante los concursos que se convocaban en estas, el desarrollo constante, el progreso material, tan en boga, entre otros factores, por las ideas del positivismo (Augusto Comte) que ya se imponían en la mentalidad de las élites decimonónicas.

Naturalmente, la idea también fue recogida por las nacientes burguesías latinoamericanas. En el Perú, la Municipalidad de Lima, bajo la iniciativa de su entonces alcalde, Manuel Pardo y Lavalle, había ya montado una exposición industrial el 28 de julio de 1869 en el local de la novísima Escuela de Artes y Oficios ${ }^{10}$. El éxito de esta primera muestra, llevó al gobierno de José Balta a impulsar otra de mayor aliento, para el cincuentenario, con la participación de países invitados, y exhibir el poder industrial, comercial y creativo del país.

Así, la comisión organizadora se reunió por primera vez el 16 de septiembre de 1869. Quedó presidida por el general y expresidente de la República Manuel Ignacio de Vivanco; Luis Mortier fue el tesorero y Juan Oviedo, el secretario provisional. Como ocurría en toda exposición de este tipo, los objetos y productos de cada sección debían entrar a una competencia. Por ello, se abrió un concurso para la introducción de maquinarias, plantas y animales destinados a incrementar la industria local ${ }^{11}$. La

9 El diseño y construcción del Parque de la Exposición de la capital peruana coincide con la ampliación o remodelación de parques públicos tan emblemáticos como el Saint James Park y Hyde Park (Londres), el Jardín de Luxemburgo (París), los Jardines del Retiro (Madrid), el Central Park (Nueva York), el Parque de Chapultepec (Ciudad de México), el Parque O'Higgins (Santiago de Chile) y los Bosques de Palermo (Buenos Aires).

10 Los detalles de aquella muestra pueden consultarse Guía de la Exposición Industrial de Lima, 28 de julio de 1869.

11 Según el Reglamento de la Exposición Nacional (1870), sus objetivos eran "reunir todos los productos naturales, las materias primeras y las modificadas, elaboradas o manufacturadas, y los diferentes animales, vegetales, minerales, obras de arte, y en general, todos los productos naturales e industriales del Perú; y provocar un concurso extranjero de modelos y máquinas aplicables a la industria agrícola o fabril, y provocar igual concurso de árboles y plantas, así como de toda clase de animales reproductores pertenecientes a las razas perfeccionadas" (p. 3). 
comisión organizadora, además, redactó un reglamento de cincuenta y cinco artículos y cuatro apartados, en el que se establecían las fechas de entrega y recibo de los objetos y productos a exponer, así como las atribuciones de los comisarios peruanos en la selección de los objetos. Luego, entre otras disposiciones, se presentó la distribución por grupos y clases que debía tener la Exposición (véase el anexo).

La inauguración de la gran Exposición Nacional estuvo prevista para el 9 de diciembre de 1870, aniversario de la batalla de Ayacucho. Sin embargo, como el proyecto excedió el presupuesto inicial, las obras se dilataron y, por no haberse terminado la construcción del Palacio, se trasladó la fecha de la apertura del montaje al 28 de julio de 1871, a cincuenta años exactos de la proclamación de la Independencia por el general San Martín: pero el Palacio aún no estaba terminado. Finalmente, todo quedó listo recién el 1 de julio de 1872, pocos días antes del trágico final del gobierno de Balta ${ }^{12}$.

A la ceremonia, asistieron los miembros de la comisión organizadora, las principales autoridades políticas, el cuerpo diplomático y personajes notables de la ciudad. No acudió el presidente Balta, quizá ya abrumado por la crisis política y los intentos conspirativos. El discurso central lo dio el polígrafo Manuel Atanasio Fuentes, quien insistió en que el propósito de construir el Palacio era el siguiente:

Ofrecer al país un monumento que acredite que, en el campo del progreso intelectual y artístico, hemos avanzado con todo el vigor de los pueblos que comprenden que, en el siglo que vivimos, la humanidad marcha con seguro paso al grado de perfeccionamiento que le es lícito alcanzar. (Fuentes, 1872, p. 87)

El siguiente discurso correspondió a Manuel Santa María, ministro de Gobierno, quien, en nombre del presidente, también destacó la capacidad del Perú en avanzar en la senda del progreso. En suma, se trataba de una fiesta del trabajo y de la industria, y de la capacidad de la ciudad de Lima, en plena etapa de modernización y expansión, para organizar este tipo de eventos, al igual que las principales ciudades de Occidente.

La resonancia que tuvo este día histórico para la joven República podemos apreciarla en el siguiente editorial de El Correo del Perú:
Un acto solemney de gran significación para el porvenir del Perú, se acaba de realizar con la apertura de la Exposición Nacional. La naciente industria peruana debe enorgullecerse de tener hoy un monumento donde ostentar los adelantos hechos mediante sus propios esfuerzos; esfuerzos ahogados unas veces por el desaliento que produce el poco estímulo, y otras por la presión del Impuesto que, sin necesidades extremas, ha arrebatado en muchas ocasiones el pan de la boca del obrero... Estos esfuerzos son más laudables aun, desde que el peruano, sin la imperiosa necesidad de tener que recurrir por hambre al trabajo, sin la duda de no poder granjearse una renta de las arcas del Estado, ha preferido conquistar en un oscuro taller, con el sudor de su frente, el título de buen ciudadano, para dejarlo como una herencia gloriosa a sus hijos y a su patria. jAdelante obreros del porvenir! Solo el trabajo da vida propia a un pueblo y el derecho para inscribirse en el mapa de las naciones cultas. (1 de julio de 1872, p. 1)

El mensaje del diario limeño era claro: el progreso se logra a través del trabajo, del esfuerzo humano y del uso de la creatividad, no de las rentas o la ayuda del Estado.

Según los testimonios de la época, la Exposición Nacional, a pesar de lo que tardó en inaugurarse, fue todo un éxito. Fue muy comentada la pintura alegórica del Perú con una inscripción que resumía el espíritu de la coyuntura del cincuentenario: “El Perú libre y soberano amigo de todas las naciones aunque independiente de ellas". En total, se presentaron 801 expositores: 623 fueron peruanos y 178 vinieron de fuera. Casi todas las provincias del Perú estuvieron representadas con sus productos. Los expositores foráneos vinieron de Chile (79), Inglaterra (39), Italia (20), Bélgica (10), Alemania (7), Francia (5), Holanda (5), Estados Unidos (2), Ecuador (2), Escocia (1), Austria (1), Dalmacia (1), Bolivia (1) y San Salvador (1) (Quiñones 2007, p. 100).

Sin embargo, de todo lo expuesto en 1872, en la memoria colectiva nacional quedó el recuerdo del reloj que ya había presentado del coronel e inventor peruano Pedro Ruiz Gallo, estrenado a las 12 de la noche del 6 de diciembre de 1870 en el Parque de la Exposición. Era una de las atracciones más populares de Lima. Con una altura de once metros, tenía nueve esferas y señalaba no solo las horas, sino también los días, los meses, los años, las estaciones, las fases de la luna, interpretaba el himno nacional e izaba la bandera peruana mientras dos centinelas mecánicos presentaban armas al son de la Marcha de Banderas. Cada hora, además, se renovaban unos

12 El costo total de la obra terminó siendo de dos millones de soles. En 1869, se proyectó un gasto de 250000 soles; al año siguiente, la comisión solicitó un aumento de 550000 soles. Para marzo de 1871, los gastos ya habían llegado al millón de soles. Una comisión nombrada por el gobierno, integrada por Enrique García Monterroso y Simón Irigoyen, se encargó de evaluar los gastos de la construcción del Palacio de la Exposición (Quiñones, 2007, pp. 84-85). 
cuadros con escenas de la historia peruana, pintados por el propio Ruiz Gallo. En su momento fue el símbolo de la creatividad de los peruanos ${ }^{13}$.

En suma, en medio de las desventuras o de la aparente riqueza, la Exposición Nacional de 1872 fue un momento de excepción en que el país, luego de cincuenta años de proclamar su vida independiente, mostraba al mudo sus riquezas naturales, la habilidad de sus artesanos y sus progresos en los campos de la ciencia y la tecnología. El espíritu que animó este esfuerzo, como se ha insistido, respondió al entusiasmo por la imagen de prosperidad que la élite de entonces pregonaba y por cierto espíritu de imitación de lo que acontecía en Londres, París o Nueva York. El Perú, en todo caso, podía ser también protagonista de esta carrera mundial hacia el progreso.

\section{El Museo Nacional}

Poco después de inaugurada la Gran Exposición, el gobierno del presidente Manuel Pardo, sucesor de Balta, creó, el 17 de diciembre de 1872, la Sociedad de Bellas Artes, entidad que tendría bajo su responsabilidad la administración del Palacio de la Exposición y sus parques, así como la defensa del patrimonio cultural monumental del país.

En ese sentido, una de sus tareas fue trasladar la colección del Museo Nacional (que hasta ese momento se encontraba en un ambiente precario de la Biblioteca Nacional) a los nuevos salones del Palacio de la Exposición ${ }^{14}$. De esta manera, la coyuntura del Cincuentenario permitió que la memoria histórica del país, herramienta fundamental del proceso nacionalizador, quedara adecuadamente administrada y exhibida en el mejor local con que contaba la capital de la República.
El Museo Nacional, creado por el presidente Torre Tagle en 1822 y puesto en funcionamiento a partir de 1826, se encontraba muy mal acondicionado en dos salas del edificio de la antigua Biblioteca Nacional, tal como lo atestiguan los viajeros europeos que lo visitaron en el siglo xIx. El viajero suizo Johann Jacob von Tshudi visitó la colección del Museo en 1842 y dejó un relato detallado de los objetos que se exponían: minerales, animales y plantas disecados y utensilios etnográficos; antigüedades del mundo virreinal y la galería de retratos de los virreyes; los retratos de Colón, San Martín y Bolívar; ocho tablas en bronce dorado con escenas de la vida de Ignacio de Loyola; un busto en mármol de Napoleón Bonaparte; una copia del Acta de la Independencia de los Estados Unidos; y una pequeña colección numismática. Concluye Tschudi:

\begin{abstract}
La mayoría de los objetos están guardados en vitrinas de vidrio. Esta pequeña colección colorida probablemente se mantendrá al nivel que conocí por mucho tiempo, ya que los medios económicos de este instituto son muy limitados en la actualidad. Por mes se le adjudican solo 32 pesos duros, los cuales no tendrá por mucho tiempo ya que este dinero tendrá que servir para pagar las deudas causadas por las frecuentes mudanzas, así como la adquisición de vitrinas, etc. El museo está abierto al público cuatro veces por semana desde las 10 hasta las 2. $(2003$, p. 79$)$
\end{abstract}

Era hora, entonces, de que aquella colección fuera trasladada a un local más adecuado, más acorde con las nuevas exigencias de la museografía decimonónica.

La élite peruana, al igual que sus pares en América Latina, era consciente de que un Museo Nacional brindaba el escenario donde representar el pasado de la nación o al menos aquello que los organizadores de la colección habían seleccionado de este pasado. El Museo debía desplegar un pasado útil para el presente,

13 El mito del invento de Ruiz Gallo, que llega hasta nuestros días, quedó inmortalizado durante la ocupación chilena de Lima en 1881. La leyenda cuenta que su constructor, sabiendo que el reloj figuraba en la lista de monumentos que los chilenos planeaban llevarse, le extrajo varias piezas importantes para evitar que volviera a funcionar. A pesar de esto, el reloj fue desmontado por órdenes de Patricio Lynch (13 de octubre de 1882) y llevado por el enemigo, aunque no volvió a ser armado en ninguna ciudad chilena. ¿Por qué? En parte porque o Ruiz Gallo o algunos patriotas le retiraron previamente algunas de sus piezas clave o porque los chilenos lo desmontaron mal, sin enumerar los cientos de piezas con que estaba construido. Como era pieza original y su funcionamiento era muy complicado, no se podían buscar repuestos y así volverlo a operar. En resumen, fue un expolio totalmente inútil para el invasor.

14 El Museo Nacional quedó bajo la responsabilidad técnica y administrativa de la Sociedad de Bellas Artes, y quedaron suprimidos los cargos de director, subdirector, conservador, colector y amanuense-celador (Ravines, 1989). Entre los miembros de la Sociedad de Bellas Artes estuvieron Manuel Atanasio Fuentes, Antonio Raimondi, Ignacio de Osma, José Antonio Barrenechea, Miceno Espantoso, José Bresani, Ernesto Malinowski, Gaspar de la Puente, Pedro Correa y Thomas Hutchinson (Quiñones, 2007, p. 89). 
pues se trataba de un espacio donde la nación podía presentarse como "comunidad imaginada". En suma, los museos (como los monumentos) eran lugares donde el nacionalismo podía encarnarse, hacerse visible (Earle, 2006).

¿Qué exhibía el Museo Nacional del Perú en el siglo xIx? Aparte de centenares de animales y aves disecados y muestras de minerales de la sierra, la colección consistía en los retratos de los virreyes; una selección muy rica de utensilios, especialmente ceramios y tejidos de las épocas inca y preincaica, colocados en cajas de vidrio; momias precolombinas de Cajatambo y Ayacucho; arcos, flechas, remos, sombreros de plumas, hachas de piedra, máscaras de terracota y la Estela de Chavín, recientemente hallada por el naturalista italiano Antonio Raimondi. Asimismo, Los Funerales de Atahualpa, obra del pintor Luis Montero, era otra de las atracciones de la colección ${ }^{15}$.

La parte medular de la muestra eran los objetos de origen prehispánico. Desde los años iniciales de la República, hubo el interés gubernamental por protegerlos y se promulgaron leyes encaminadas a mantenerlos dentro de las fronteras nacionales. Tal legislación ligaba la preservación de las antigüedades precolombinas al prestigio nacional, pues eran la prueba de la grandeza de las civilizaciones anteriores a la conquista y, por lo tanto, tenían importancia para el Estado republicano, que se presentaba como una reivindicación del imperio incaico y demás pueblos precolombinos. El Museo Nacional, en consecuencia, era un libro de historia patria que exponía la memoria nacional (Earle, 2006). Cabe añadir que, hacia la década de 1870, el creciente aprecio que los intelectuales tenían por los artefactos precolombinos se debía no solo a las exigencias del proceso nacionalizador, sino también al desarrollo de la arqueología como disciplina académica, y que varios viajeros o cronistas extranjeros que llegaron al Perú se habían encargado de divulgar en diversas exposiciones en Europa y Norteamérica.

En suma, consideramos que el traslado de esta colección al Palacio de la Exposición sería la culminación de un proceso iniciado desde la Independencia, cuando las élites asumieron el pasado prehispánico porque representaba la base legitimadora de su soberanía. Sin embargo, esta apropiación de los ancestros lejanos la asumieron con un código muy particular, es decir, idealizado y desconectado del mundo indígena del presente, ya arcaico, mudo y arruinado (envilecido) desde la invasión europea del siglo xvı (Gänger, 2009).

15 El inventario más completo de lo que exhibía el Museo Nacional en 1872 se lo debemos al viajero inglés Thomas Joseph Hutchinson, cuyo texto ha sido recientemente reproducido, con un valioso estudio crítico, en una revista actual de arte y cultura (Hutchinson, 2015). 


\section{ANEXO}

\section{GRUPOS Y SECCIONES DE LA EXPOSICIÓN NACIONAL DE 1872}

\begin{tabular}{|c|c|}
\hline Grupo & Secciones \\
\hline I: Artes liberales & $\begin{array}{l}\text { Pinturas al óleo, pinturas diversas y dibujos, esculturas y } \\
\text { grabados, dibujos y modelos de arquitectura, litografía. }\end{array}$ \\
\hline II: Material y aplicaciones de las artes liberales & $\begin{array}{l}\text { Obras de imprenta y literatura; útiles de escritorio, } \\
\text { encuadernación; material de pintura y dibujo, y obras } \\
\text { de papel; aplicaciones del dibujo y de la plástica a las } \\
\text { artes usuales; pruebas fotográficas; instrumentos de } \\
\text { música; aparatos e instrumentos de medicina; ambu- } \\
\text { lancias civiles y militares; material para la enseñanza } \\
\text { de las ciencias médicas; cartas y aparatos de geografía } \\
\text { y cosmografía. }\end{array}$ \\
\hline III: Menaje y otros objetos destinados a la habitación & $\begin{array}{l}\text { Menaje, ornatos, alfombras y otros objetos para habi- } \\
\text { taciones; platería; obras de arte en bronce y otros } \\
\text { metales; relojería; aparatos para el alumbrado y abrigo } \\
\text { de habitaciones; perfumería; obras de marroquín, } \\
\text { tornería y cestería. }\end{array}$ \\
\hline $\begin{array}{l}\text { IV: Vestidos, tejidos para vestidos y otras prendas de } \\
\text { uso personal }\end{array}$ & $\begin{array}{l}\text { Hilos y tejidos de algodón, hilos y tejidos de lino y } \\
\text { otras fibras vegetales equivalentes, hilos y tejidos } \\
\text { de lana cardada, hilos de seda, encaje, blondas, } \\
\text { bordados, pasamanería y briscados, ropa de lienzo } \\
\text { y prendas accesorias al vestido, vestidos de ambos } \\
\text { sexos, joyería, armas portátiles, utensilios de viaje y } \\
\text { campamento, juguetes. }\end{array}$ \\
\hline $\begin{array}{l}\text { V: Productos brutos y elaborados de las industrias } \\
\text { extractivas }\end{array}$ & $\begin{array}{l}\text { Productos de laboreo de minas y metales; producto } \\
\text { del beneficio de bosques e industrias procedentes; } \\
\text { productos de la casa, de la pesca y de las cosechas sin } \\
\text { cultivo; productos de agricultura de fácil conservación; } \\
\text { productos químicos y farmacéuticos; tintorería, pieles } \\
\text { y corambre. }\end{array}$ \\
\hline
\end{tabular}




\begin{tabular}{|c|c|}
\hline $\begin{array}{l}\text { VI: Instrumentos y procedimientos empleados en las } \\
\text { artes usuales }\end{array}$ & $\begin{array}{l}\text { Material para el laboreo de las minas; material y proce- } \\
\text { dimientos de la industria rural; instrumentos de caza } \\
\text { y pesca; material y procedimientos aplicables a la } \\
\text { preparación de sustancias alimenticias; motores gene- } \\
\text { radores y aparatos mecánicos, máquinas y aparatos de } \\
\text { mecánica general; material y procedimientos de hilar } \\
\text { y torcer cuerdas; material y procedimientos de tejedu- } \\
\text { ría; máquinas, instrumentos y procedimientos usados } \\
\text { en diversas industrias; carrocería; talabartería; ferroca- } \\
\text { rriles; material y procedimientos usados en las obras } \\
\text { públicas y en la construcción de edificios, y material } \\
\text { para la navegación. }\end{array}$ \\
\hline VII: Alimentos frescos y conservados & $\begin{array}{l}\text { Cereales y otros productos farináceos, comestibles y } \\
\text { sus derivados, panadería y pastelería, materias graso- } \\
\text { sas y pastelería, carnes y pescados, legumbres y frutos, } \\
\text { condimentos y estimulantes, azúcar y confituras, } \\
\text { bebidas fermentadas. }\end{array}$ \\
\hline $\begin{array}{l}\text { VIII: Modelos de construcciones rústicas y animales } \\
\text { vivos }\end{array}$ & $\begin{array}{l}\text { Modelos de oficinas rústicas para el beneficio de los } \\
\text { productos de la agricultura; caballos, asnos y mulas; } \\
\text { animales vacunos y lanares; puercos y conejos, aves } \\
\text { domésticas, perros, insectos, animales de mar. }\end{array}$ \\
\hline $\begin{array}{l}\text { IX: Árboles, plantas y modelos de sus correspondientes } \\
\text { cultivos }\end{array}$ & $\begin{array}{l}\text { Invernáculos y material de horticultura, flores y plantas } \\
\text { de adorno, hortalizas, frutas y árboles frutales, semillas } \\
\text { y plantas de árboles de bosque, plantas de invernáculo, } \\
\text { plantas medicinales. }\end{array}$ \\
\hline $\begin{array}{l}\text { X: Objetos destinados a mejorar las condiciones físicas } \\
\text { y morales de los pueblos }\end{array}$ & $\begin{array}{l}\text { Material y métodos empleados en la enseñanza de } \\
\text { los niños, bibliotecas y material de la enseñanza } \\
\text { que se da a los adultos en la familia, en los talleres y } \\
\text { municipios; trastos, vestidos y alimentos de cualquier } \\
\text { origen, notables por sus cualidades útiles junto a su } \\
\text { baratura; muestras de todos los trajes populares del } \\
\text { Perú; modelos de habitaciones notables por su bara- } \\
\text { tura, salubridad y comodidad; obras de toda clase } \\
\text { trabajadas por maestros de oficio; instrumentos y } \\
\text { procedimientos empleados por los artesanos que } \\
\text { trabajan de su propia cuenta. }\end{array}$ \\
\hline
\end{tabular}

Fuente: Quiñones (2007, pp. 81-82) 


\section{Referencias}

BASADRE, J. (2005). Historia de la República del Perú, 1822-1933 (vol. 6). Lima: El Comercio.

Bromley, J., y BARBAGelatA, J. (1945). Evolución urbana de Lima. Lima: Editorial Lumen y Consejo Provincial de Lima.

[Editorial]. (1 de julio de 1872). El Comercio, p. 1.

FUENTES, F. (1872). Catálogo de la Exposición Nacional de 1872. Lima: Imprenta del Estado.

TschudI von, J. (2003). Esbozos de viajes realizados entre 1838 y 1842. Lima: Pontificia Universidad Católica del Perú.

\section{Bibliografía}

EARLE, R. (2006). Monumentos y museos: la nacionalización del pasado precolombino durante el siglo xIX. En B. Gonzáles Stephan y J. Andermann (Eds.), Galerías del progreso. Museos, exposiciones y cultura visual en América Latina (pp. 27-64). Rosario: Beatriz Viterbo Editora.

FloRes-ZúÑIGA, F. (2008). Haciendas y pueblos de Lima. Historia del valle del Rímac (de sus orígenes al siglo xx) (t. I.). Lima: Fondo Editorial del Congreso del Perú y Municipalidad Metropolitana de Lima.

GÄNGER, S. (2009). Estas reliquias de mis antepasados: saber y poder en la historia de la arqueología peruana en el siglo XIX. Ponencia para el Congreso de la Asociación de Estudios Latinoamericanos. Río de Janeiro, junio 11-14.

García Bryce, J. (1980). La arquitectura en el Virreinato y la República. En Historia del Perú (vol. 9) (pp. 11-166). Lima: Juan Mejía Baca.

Guía de la Exposición Industrial de Lima, 28 de julio de 1869. (1869). Lima: Imprenta de El Comercio.

GÜNTHER, J., y LOHMANn, G. (1992). Lima. Madrid: Mapfre.

Hutchinson, T. J. (2015). Palacio de la Exposición de Lima (1872). Kaypunku, 2(1), 267-285.

QUIÑONES, L. (2007). El Perú en la vitrina. El progreso material a través de las exposiciones (1851-1893). Lima: Universidad Nacional de Ingeniería.

RAvines, R. (1989). Los museos del Perú. Breve historia y guía. Lima: Instituto Nacional de Cultura.

Reglamento de la Exposición Nacional del Perú formado por la Comisión Central y aprobado por el Supremo Gobierno (1870). Lima: Imprenta del Estado.

\section{Periódicos \\ El Correo del Perú \\ LaPatria}

